\title{
The Effects of Conformity on Women's Body Images Under Different Social Norms and Different Cultures
}

\author{
Jingyi Zhang ${ }^{1, a}$
}

\author{
${ }^{1}$ University of Washington \\ azjingyi0420@gmail.com
}

\begin{abstract}
When young children hear stories about Wallis Simpson, the Duchess of Windsor, they always remember that "No woman will dislike being too thin and having too much money" as a cliche. Like Wallis, staying skinny under today's Western culture, especially the American culture, advocates strongly the conformity on women's body image[9]. Normative social influence has huge effects of conformity on women's body image, which makes women strive to pursue the attractive figure prescribed by culture. Different countries have different conformity on women's body images while most countries treat fat as beauty. Almost every woman from different cultures is pursuing the attractive figure prescribed by their culture and never feels confident about their body. This shows that almost every woman is affected by conformity on their body images under different social norms and cultures. However, to fit in this body conformity, many people used extreme ways, like almost not eating anything or even worse. This paper aims to analyzes the effects of conformity on women's body images under different social norms and different cultures. Many people think the affections on women's body images could push women to have a healthier lifestyle. However, it is not necessary to chase body conformity blindly.
\end{abstract}

Keywords: Social Norm, mass media, conformity, body image, mental health.

\section{INTRODUCTION}

Nowadays, women care about their conformity to their body images, affecting by different social norms and different cultures. Women are willing to change their bodies to conform to the beauty standard in society, even doing dangerous things. Normative social influence has huge effects of conformity on women's body images, which makes women strive to pursue the attractive figure prescribed by culture. Mostly, women got the body conformity changing by the social media. Researchers have investigated how body image conformity is brought to women, but it seems like women are still chasing the changeable body images in society. Dissatisfaction with the body and excessive investment in the body are precursors to a series of unhealthy eating behaviors, including overeating, restrictive eating, and self-inducing vomiting[12]. Excessive attention to weight and body type has been identified as important risk factors for the development of eating disorders and has been included as the diagnostic criteria for anorexia and bulimia [13]. In addition, dissatisfaction with body image and depression, stress, low self-esteem, increased negative emotions, decreased evaluation of one's physical attractiveness, global shame, increased social anxiety, emotional distress, appearance contemplation, and unnecessary appearance management tendencies [6]. The tripartite Influence Model will be used in this research to analyze the development of dissatisfaction with body images under current social conformity. This research aims to encourage women to accept their body images and not hurt themselves mentally and physically for trying to fit in the social body images conformity.

\section{TRIPARTITE INFLUENCE MODEL}

One of the most commonly used theories to explain the unsatisfactory development of body image is the tripartite influence model [23]. The model proposes that three influences, which are peers, parents, and media, affected body image and dietary issues through two mediating mechanisms: the internalization of social standards for appearance and excessive appearance comparison. According to the tripartite influence model, social influences such as age, family, and media pressure, individuals adhere to culturally defined beauty standards [7]. After constant exposure to this information, celebrities become part of the individual's personal 
beliefs about attractiveness and beauty. Individuals begin to internalize their appearance idols, which they eventually interpret as self-derived. Those who internalize the dominant information in the social and cultural environment to a greater extent, but at the same time do not feel that they meet the standards, are at higher risk of dissatisfaction with body image [24]. The internalization of thin celebrities is the basic concept of a complete understanding of dissatisfaction with body image. Studies from Suisman et al. [23] that the internalization of lean ideals is directly related to physical dissatisfaction and eating disorder symptoms. In addition, it has been found that thin internalization can regulate the relationship between sociocultural influence and physical dissatisfaction [10].

\section{ANALYSIS}

\subsection{Physical effects}

The current social and cultural pressures that force women to keep weight and lose weight can have serious consequences, even fatal. Those pressures cause some women to maintain unrealistic perfect bodies through unhealthy diet and exercise habits [2]. Conformity includes informative social influence and normative social influence [1]. Normally the influence for people fitting in the conformity of body images is normative social influence, that conforms because people want to be liked or accepted by others. Based on research in 1986, the last time weight loss became the conformity for a female attractive figure was in the mid-20th century with a spread of an epidemic of eating disorders [20]. Insane weight loss also appears in younger girls. Several studies have provided support for tripartite impact models among young girls and women [19]. In addition to body image disorders and eating disorders, the tripartite impact model is also very suitable for explaining women's various physical management habits, such as tanning and exercise, and attitudes towards cosmetic surgery [18]. In 2000, a research survey by the American Anorexia Bulimia Association found that $1 / 3$ of girls aged from twelve to thirteen are actively trying to lose weight through dieting, vomiting, diarrhea, and using weightloss drugs[2] [17]. Due to this insane weight-losing activity, many girls died and got serious diseases that time, which hurt body and teenager's development as the researchers concluded. Everyone has the right to chase beauty, however, it is crucial to choose the right way and avoid hurting bodies under the effects of conformity of women's body shapes.

\subsection{Mental effects}

Despite the negative effects on human health, the conformity of attractive women's bodies images may lead to the results of unconfidence and abnormal psychology under conformity pressure. In the last few decades, the standards of attractive figures for women in other non-American cultures have also undergone changes in conformity of women's beauty. In order to fully understand the body image in different cultures, it is necessary to understand the social-cultural norms. Social-cultural rules are the rules or expectations of behavior and thinking based on common beliefs about gender roles in these specific cultural groups [22]. Because people have integrated into the gender ideology of the community and the rules about how men and women should think and behave, they accept these norms on the surface. These values and norms can directly affect the way power is distributed in society, which is a typical disadvantage of women in most patriarchal societies [12] Therefore, men's perception of femininity and beauty has not only become a preference, but also a standard of pursuit. For example, traditional gender roles associate femininity with beauty and attention with appearance [11]. In fact, among young women, the concept of femininity is positively related to the importance of appearance. This finding suggests that compared to women with non-traditional attitudes, attractive appearances may be more important for women who identify with traditional gender role attitudes [8]. Therefore, women's traditional attitudes towards the relationship between men and women may secretly require her to possess and display the physical and behavioral characteristics that she considers attractive to men. After World War two, Japan's conformity to popular appearance is affected by a more American tendency. This conformity tendency treats women's slender legs and thin bodies as beauty, which is also called hatou thin [16]. This cultural shift had impacted Japanese women to some degree as Japanese society is defined as a patriarchal society after World War Two. Japanese women got the strong normative conformity pressure to stay skinny and had feelings of unconfident. In fact, the researchers analyzed and compared Japanese and American college-age women and figured out that Japanese women always thought that they were too obese more than American women thought about themselves [15]. Meanwhile, Japanese women are also more dissatisfied with their bodies than American women although Japanese women are normally thinner than American women on average [15]. In addition, the researchers found that the "the needs for social identity" can better predict the eating disorders of Japanese women, but it is not applicable to American women. Compared with American culture, Japanese culture is more submissive for women, so maintaining a slim norm will have more serious consequences for Japanese women [16]. This pressure causes Japanese women unconfident with many psychological diseases like eating disorders, as one of the negative effects of women's body images conformity. 


\section{3. changeable body images conformity}

The conformity of women celebrities' body shapes images might change current conformity body images in different eras, which is also how women know the type of attractive figure that their culture identified at a specific moment as the conformity of body images changing[20]. Body images conformity might change due to the different popular actresses in different eras. At the beginning of the 20th century, there were beautiful women with plump bodies. In the 1920s, it was the era of actress "Frivolous Girl". At that time, Frivolous Girl's appearance conformity was flat-chested and slender. Body conformity changed in the 1940s due to actresses such as "Pier Girl" Betty Grable. At that time, body conformity was the standard for a pretty plump body. In the 1950s, Marilyn Monroe was sought after by the world, and her figure conformity had lines and beautiful curves. Twiggy becomes the new conformity of women's bodies in the 1960s with skinny bodies. This extremely skinny body had continued for the longest time during the 20th as the conformity of women's body images [3]. From this time on, women have been conveying body shape conformity through various forms of media, from magazine advertisements to TV scenes and comedies: women's ideal images are extremely skinny. Women tend to be overweight and their conscious weight is heavier than their actual weight[4]. If they have just seen images of slim women on social media or met them in person, this effect will increase. For American advertising models or actors, their figure requirements are more stringent than those of non-media women. In different eras, the body images of different popular celebrities could change the conformity of body images via different media.

\section{CONCLUSION}

The impact of conformity on Women's Body images under Different Social Norms and Different Cultures seems will never end. Almost every woman is affected by conformity on their body images under different social norms and cultures with changing of conformity in different eras. One aspect affected women body and health is women trying to lose weight in wrong ways. Another effect is unhealthy mental to be unconfident and think themselves as "Not a conformity beauty". Finally, people will follow the social media women or actresses as the conformity beauty in different eras. In this essay, mostly the negative effects are towards extremely skinny bodies. Women should be suggested to value health than body images conformity. At the same time, pressures from different cultures, social norms, and social media should stop damaging women's health but encourage women to stay healthy. It is meaningful and necessary for people to do further research about how to stop women's pressure about their body images, either from peer pressure or social media. If one day the women's body conformity becomes extremely fat, it is interesting to think about what women do in that era.

\section{REFERENCES}

[1]Aronson, J., \& Aronson, E. (2020). Readings about the social animal. New York, NY: Worth.

[2]Barber, A. E. (1998). Recruiting employees: Individual and organizational perspectives. Sage Publications.

http://dx.doi.org/10.4135/9781452243351

[3]Bearman, S. K., Stice, E., \& Chase, A. (2003). Evaluation of an intervention targeting both depressive and bulimic pathology: A randomized prevention trial. Behavior Therapy, 34(3), 277-293. https://doi.org/10.1016/S0005-7894(03)80001-1

[4]Cohn, L. D., \& Adler, N. E. (1992). Female and male perceptions of ideal body shapes: Distorted views among Caucasian college students. Psychology of women quarterly, 16(1), 69-79. https://doi.org/10.1111/j.14716402.1992.tb00240.x

[5]Ellin, J. (2000). Restitutionism defended. In Liberalism (pp. 151-169). Springer, Dordrecht. https://doi.org/10.1007/978-94-015-9440-0_10

[6]Etu, S. F., and Gray, J. J. (2010). A preliminary investigation of the relationship between induced rumination and state body image dissatisfaction and anxiety.Body Image7, 82-85. doi: 10.1016/j.bodyim.2009.09.004

[7]Grabe, S., Ward, L. M., and Hyde, J. S. (2008). The role of the media in body image dissatisfactions among women: a meta-analysis of experimental and correlational studies.Psychol. Bull.134:460. Doi: 10.1037/0033-2909.134.3.460

[8]Green, M. A., Davids, C. M., Skaggs, A. K., Riopel, C. M., and Hallengren, J. J. (2008). Femininity and eating disorders.Eat. Disord.16, 283-293. doi: 10.1080/10640260802115829

[9]Grossbard, J. R., Lee, C. M., Neighbors, C., \& Larimer, M. E. (2009). Body image concerns and contingent self-esteem in male and female college students. Sex roles, 60(3-4), 198-207. https://doi.org/10.1007/s11199-008-9535-y

[10]Keery, H., Van den Berg, P., and Thompson, J. K. (2004). An evaluation of the tripartite influence model of body image dissatisfaction and eating disturbance with adolescent girls.Body Imagel, 237-251. doi: 10.1016/j.bodyim.2004.03.001

[11]Lennon, S. J., Rudd, N. A., Sloan, B., and Kim, J. S. (1999). Attitudes toward gender roles, self-esteem, 
and body image: application of a model.Clothing Textiles Res. J.17, 191-202. doi: 10.1177/0887302x9901700403

[12]Levine, M. P., and Piran, N. (2004). The role of body image in the prevention of eating disorders.Body Image 1, 57-70. doi: 10.1016/s1740-1445(03)00006

[13]Lydecker, J. A., White, M. A., and Grilo, C. M. (2017). Form and formulation: examining the distinctiveness of body image constructs in treatment-seeking patients with binge-eating disorder. J. Consult. Clin. Psychol.85, 1095. doi: 10.1037/ccp0000258

[14]Marcus, R., and Harper, C. (2014). Gender Justice and Social Norms-Processes of Change for Adolescent Girls.London: Overseas Development Institute.

[15]Mukai, T., \& Mccloskey, L. A. (1996). Eating Attitudes among Japanese and American Elementary Schoolgirls. Journal of Cross-Cultural Psychology, 27(4), 424-435. https://doi.org/10.1177/0022022196274003

[16]Mukai, T., Kambara, A., \& Sasaki, Y. (1998). Body dissatisfaction, need for social approval and eating disturbances among Japanese and American college women. Sex Roles: A Journal of Research, 39(9-10), 751-763.

https://doi.org/10.1023/A:1018812218467

[17]Reijonen, J. H., Pratt, H. D., Patel, D. R., \& Greydanus, D. E. (2003). Eating Disorders in the Adolescent Population:: An Overview.Journal of Adolescent Research,18(3), 209222. https://doi.org/10.1177/074355840301800300 2

[18]Sharp, G., Tiggemann, M., and Mattiske, J. (2014). The role of media and peer influences in Australian women's attitudes towards cosmetic surgery.Body Image11, 482-487. doi: 10.1016/j.bodyim.2014.07.009

[19]Shroff, H., and Thompson, J. K. (2006). The tripartite influence model of body image and eating disturbance: a replication with adolescent girls.Body Image3, 17-23. doi: 10.1016/j.bodyim.2005.10.004

[20]Silverstein, B., Perdue, L., Peterson, B., \& Kelly, E. (1986). The role of the mass media in promoting a thin standard of bodily attractiveness for women. Sex roles, 14(9-10), 519-532. https://doi.org/10.1007/BF00287452

[21]Silverstein, B., Perdue, L., Peterson, B., Vogel, L., \& Fantini, D. A. (1986). Possible causes of the thin standard of bodily attractiveness for women.
International Journal of Eating Disorders, 5(5), 907-916. 1

[22]Strahan, E. J., Wilson, A. E., Cressman, K. E., and Buote, V. M. (2006). Comparing to perfection: how cultural norms for appearance affect social comparisons and self-image.Body Image3, 211227. doi: 10.1016/j.bodyim.2006.07.004

[23]Suisman, J. L., O’Connor, S. M., Sperry, S., Thompson, J. K., Keel, P. K., Burt, S. A., et al. (2012). Genetic and environmental influences on thin-ideal internalization.Int. J. Eat. Dis.45, 942948. doi: 10.1002/eat.22056

[24]Thompson, J. K., and Stice, E. (2001). Thin-ideal internalization: mounting evidence for a new risk factor for body-image disturbance and eating pathology.Curr. Dir. Psychol. Sci.10, 181-183. doi: $10.1111 / 1467-8721.00144$ 